\title{
RESÍDUO DA POLPA DO MARACUJÁ COMO ALIMENTO ALTERNATIVO PARA CODORNAS EUROPEIAS FÊMEAS ${ }^{1}$
}

\author{
Romilton Ferreira de Barros Júnior², Geraldo Roberto Quintão Lana3, Sandra Roselí Valerio Lana ${ }^{3}$, Ana \\ Patrícia Alves Leão ${ }^{4}$, Iva Carla de Barros Ayres ${ }^{5}$, Daniel Silva Santos ${ }^{5}$, Luiz Arthur dos Anjos Lima ${ }^{6}$, Wilson \\ Araújo da Silva ${ }^{6}$
}

\author{
${ }^{1}$ Parte da dissertação do primeiro autor. \\ ${ }^{2}$ Mestre em Zootecnia - CECA/UFAL. E-mail: romilton.barros@bol.com.br \\ 32Docente do Programa de Pós-Graduação em Zootecnia - CECA/UFAL. E-mail: sandraroselilana@gmail.com; geraldoquintaolana@ \\ gmail.com. \\ ${ }_{4}^{4}$ Doutoranda do Programa de Pós-Graduação em Zootecnia - UFLA. E-mail: anapatriciaalvesleao@gmail.com \\ ${ }^{5}$ Graduando(a) em Zootecnia - CECA/UFAL. E-mail: ivacarlabarros@gmail.com; daniel_silva_15@hotmail.com. \\ 6Mestrando em Zootecnia - CECA/UFAL. E-mail: luisarthur_@hotmail.com; araujodasilva.wilson869@gmail.com
}

\begin{abstract}
RESUMO: Na coturnicultura, a alimentação é o fator que mais onera os custos da criação. Deste modo, estudos com alimentos alternativos, ao milho e farelo de soja, tem crescido consideravelmente. 0 objetivo do estudo foi avaliar diferentes níveis do resíduo da polpa de maracujá (RPM) na alimentação de codornas fêmeas sobre características de carcaça aos 35 dias de idade. 0 experimento foi realizado no setor de coturnicultura do CECAUFAL. Foram utilizadas 225 codornas europeias, em um delineamento experimental inteiramente casualizado com cinco tratamentos (0,0\%; 3,0\%; 6,0\%; $9,0 \%$ e 12,0\% de inclusão do RPM), cinco repetições e nove aves por unidade experimental. Aos 35 dias de idade, após jejum de seis horas, duas aves, com peso médio de cada unidade experimental foram abatidas, depenadas e evisceradas para os procedimentos de análises. Os parâmetros avaliados foram: pesos absolutos e relativos de carcaça, cortes nobres (peito e pernas) e vísceras comestíveis (coração, fígado e moela). Houve efeito significativo $(p<0,05)$, apenas para peso absoluto (g) e relativo (\%) do peito. De acordo com os resultados obtidos, é possível a inclusão do RPM, em até 12\%, sem comprometer as características de carcaça, corte nobres e vísceras comestíveis, de codornas fêmeas aos 35 dias de idade.
\end{abstract}

Palavras-chave: agroindústria, alimento alternativo, coturnicultura, metabolismo, nutrição

\section{PASSION-FRUIT PULP RESIDUE AS ALTERNATIVE FOOD FOR FEMALE EUROPEAN QUAILS}

\begin{abstract}
In coturniculture, food is the most costly factor of creation. Thus, studies with alternative foods to corn and soybean meal have grown considerably. The objective of the study was to evaluate different levels of passion-fruit pulp residue (RPM) in female quail feeding on carcass characteristics at 35 days of age. The experiment was carried out in the field of coturniculture of the CECA-UFAL. Were used twenty-five european quails in a completely randomized experimental design with five treatments $(0.0 \%, 3.0 \%, 6.0 \%, 9.0 \%$ and $12.0 \%$ RPM inclusion), five replicates and nine treatments birds per experimental unit. At 35 days of age, after six hours of fasting, two birds with average weight of each experimental unit were slaughtered, plucked and eviscerated for the analysis procedures. The parameters evaluated were: absolute and relative weights of carcass, noble cuts (chest and legs) and edible viscera (heart, liver and gizzard). There was a significant effect $(P<0.05)$, only for absolute $(\mathrm{g})$ and relative $(\%)$ of the breast. According to the results, it is possible to include RPM, up to $12 \%$, without compromising the carcass characteristics, cutting noble and edible viscera, of female quails at 35 days of age.
\end{abstract}

Keywords: agroindustry, alternative foods, coturniculture, metabolism, nutrition 


\section{INTRODUÇÃO}

A coturnicultura é uma atividade que se destaca com 0 grande crescimento na produção de carne e ovos, sendo estes, produtos que representam uma excelente fonte de proteína animal para seres humanos. (SANTOS et al., 2017).

Na criação de codornas, cerca de $70 \%$ dos custos de produção são com a alimentação, de modo que para minimizar esses custos, tem sido crescente as pesquisas cientificas com alimentos alternativos, que possam substituir, o milho ou o farelo de soja, que são os ingredientes mais utilizados na formulação de rações destas aves.

0 processamento das frutas, por agroindústrias, produz uma grande quantidade de resíduos, que se descartados de forma inadequada, podem gerar poluição ambiental. Porém, a maioria destes subprodutos possuem valores nutritivos e podem ser utilizados na alimentação animal (GOES et al., 2008).

Neste contexto, destaca-se o resíduo da polpa do maracujá, que se apresenta como fonte de ácidos graxos essenciais, carboidratos, proteínas e minerais (FERRARI et al., 2004).

Portanto, o objetivo da pesquisa foi avaliar os diferentes níveis do resíduo da polpa do maracujá em rações para codornas de corte fêmeas, sobre o rendimento de carcaça, cortes nobres e vísceras comestiveis, de um a 35 dias de idade.

\section{MATERIAL E MÉTODOS}

0 experimento foi realizado no setor de Coturnicultura do CECA/UFAL, localizado em Rio Largo - AL.

Foram utilizadas 225 codornas europeias (Coturnix coturnix), com um dia de idade. As aves foram alojadas em gaiolas, em um galpão de alvenaria fechado, durante o período de um a 35 dias de idade. Cada gaiola possuía comedouros tipo calha, bebedouros tipo sifão, e bandejas coletoras de excretas.
0 delineamento experimental utilizado foi 0 inteiramente casualizado com cinco tratamentos (0; 3; 6; 9 e 12\% de inclusão do resíduo da polpa do maracujá), cinco repetições e nove aves por parcela. As aves receberam rações isocalóricas e isoproteicas, apresentando em sua composição $2950 \mathrm{kcal} / \mathrm{kg}$ de energia metabolizável e $23 \%$ de proteína bruta de acordo com as exigências nutricionais para codornas europeias preconizadas por Silva e Costa (2009). 0 fornecimento de água e de ração foi à vontade durante o período de um a 35 dias de idade.

0 monitoramento das variáveis climáticas foi realizado diariamente, às 8:00 e às 16:00 horas. As médias das variáveis foram: temperatura máxima $27,55{ }^{\circ} \mathrm{C}$, temperatura mínima $26,05{ }^{\circ} \mathrm{C}$, umidade relativa $77 \%$ e o índice de temperatura de globo negro e umidade 76,11 , calculado de acordo com a fórmula proposta por Buffington et al. (1981).

Aos 35 dias de idade foram selecionadas duas codornas, de peso médio vivo de cada unidade experimental e submetidas a jejum de sólidos durante seis horas. Logo após, foram abatidas, depenadas, evisceradas, e efetuados os cortes e pesagens. Os parâmetros avaliados foram: peso ao abate (g), peso absoluto (g) e relativo (\%) da carcaça, de cortes nobres (peito e pernas) e das vísceras comestíveis (coração, fígado e moela).

As análises estatísticas foram realizadas utilizando o programa Sisvar (FERREIRA, 2014).

Todos os procedimentos deste estudo foram aprovados pelo Comitê de Ética no uso de animais da UFAL, sob número de protocolo 12/2018.

\section{RESULTADOS E DISCUSSÃO}

Os resultados referentes aos pesos absolutos e relativos de codornas de corte fêmeas e vísceras comestíveis aos 35 dias de idade estão apresentados na tabela 1. 
Tabela 1. Valores de peso absoluto $(\mathrm{g})$ ao abate, peso absoluto $(\mathrm{g})$ e relativo (\%) de carcaça, cortes nobres e vísceras comestíveis de codornas de corte fêmeas aos 35 dias alimentadas com diferentes níveis de resíduo da polpa do maracujá.

\begin{tabular}{cccccccc}
\hline Variáveis & \multicolumn{7}{c}{ Níveis de inclusão do resíduo da polpa do maracujá } \\
\hline Peso Absoluto (g) & $\mathbf{0} \%$ & $\mathbf{3} \%$ & $\mathbf{6} \%$ & $\mathbf{9 \%}$ & $\mathbf{1 2} \%$ & $\mathbf{p}$-valor & $\mathbf{C V}(\%)$ \\
\hline Abate & 250,80 & 248,00 & 249,60 & 250,40 & 251,60 & 0,99 & 5,60 \\
Carcaça & 187,22 & 189,50 & 188,68 & 195,22 & 188,88 & 0,73 & 5,12 \\
Peito* & 74,14 & 75,16 & 82,00 & 84,12 & 80,60 & 0,03 & 6,89 \\
Pernas & 39,74 & 41,46 & 39,30 & 40,68 & 40,70 & 0,92 & 9,91 \\
Fígado & 6,04 & 7,14 & 7,36 & 6,12 & 6,38 & 0,67 & 16,46 \\
Coração & 2,08 & 2,24 & 2,02 & 2,16 & 2,26 & 0,32 & 9,48 \\
Moela & 4,81 & 5,66 & 4,82 & 5,10 & 5,16 & 0,18 & 11,61 \\
\hline Peso Relativo (\%) & & & & & & & \\
\hline Carcaça & 74,60 & 76,53 & 75,62 & 77,95 & 75,25 & 0,46 & 3,92 \\
Peito* & 39,57 & 39,86 & 42,65 & 43,08 & 42,64 & 0,01 & 4,62 \\
Pernas & 21,19 & 21,86 & 20,83 & 20,86 & 21,55 & 0,84 & 7,81 \\
Fígado & 3,26 & 3,74 & 3,91 & 3,15 & 3,38 & 0,65 & 16,60 \\
Coração & 1,11 & 1,18 & 1,07 & 1,11 & 1,20 & 0,13 & 7,58 \\
Moela & 2,57 & 2,99 & 2,55 & 2,61 & 2,74 & 0,18 & 1,40 \\
\hline
\end{tabular}

*Efeito significativo $(p<0,05)$; CV - Coeficiente de variação

Houve efeito significativo $(p<0,05)$, apenas para peso absoluto (g) e relativo (\%) do peito, com resposta quadrática conforme as equações de regressão: $\hat{Y}=$ $-0,9857 x^{2}+8,1023 x+65,74\left(R^{2}=0,81\right)$ e $\hat{Y}=-0,2729 x^{2}$ $+2,5731 x+36,842\left(R^{2}=0,85\right)$, respectivamente.

Porém, os maiores valores de peso absoluto e relativo de peito, foram verificados em codornas alimentadas com os níveis do resíduo da polpa do maracujá, demonstrando assim, que não houve comprometimento no rendimento de carcaça dessas aves.

A diferença encontrada no peso absoluto e relativo do peito pode estar associada a uma despadronização no momento do corte, e não à influência dos níveis de inclusão do subproduto testado, uma vez que os demais cortes não foram influenciados pelos níveis de inclusão do resíduo ( $p>0,05)$.

Zanetti et al. (2017), conduziram estudos objetivando avaliar os efeitos da inclusão do resíduo da semente do maracujá em dietas para frangos de corte, e observaram que aos 42 dias de idade, foi possivel a inclusão em até $12,5 \%$, sem comprometer o rendimento de carcaça das aves.

\section{CONCLUSÕES}

De acordo com os resultados obtidos, é possível a inclusão do resíduo da polpa do maracujá, em até $12 \%$, sem comprometer as características de carcaça, corte nobres e vísceras comestíveis, de codornas fêmeas aos 35 dias de idade.

\section{AGRADECIMENTOS}

À Coordenação de Aperfeiçoamento de Pessoal de Nível Superior (CAPES), pelo fomento à pesquisa na forma de concessão de bolsa de mestrado.

\section{REFERÊNCIAS}

BUFFINGTON, D. E.; COLLAZO - AROCHO, A.; CANTON, G. H. et al. Black globehumidity index (BGHI) as comfort equation for dairy cows. Transaction of the American Society of Agricultural Engineering, 1981, 24, 711-714.

FERRARI, R.A.; COLUSSI, F.; AYUB, R.A. Caracterização de subprodutos da industrialização do maracujá - Aproveitamento das sementes. Revista Brasileira de Fruticultura, 2004, 26, 101-102.

FERREIRA, D. F. Sisvar: a Guide for its Bootstrap procedures in multiple comparisons. Ciência e Agrotecnologia. 2014, 38, 109-112. 
GOES, R. H. T. B.; TRAMONTINI, R. C. M.; ALMEIDA, SILVA, J. H. V.; COSTA, F. G. P. Tabela para codornas G. D. Degradabilidade ruminal da matéria seca e japonesas e europeias. 2.ed. Jaboticabal, SP: FUNEP, proteína bruta de diferentes subprodutos agroindustriais utilizados na alimentação de bovinos. Revista brasileira de saúde e produção animal, 2008, 9, 715-725. 2009. 110p.

ZANETTI, L. H.; MURAKAMI, A. E.; DIAZ-VARGAZ, M; GUERRA, A. F. Q. G.; NASCIMENTO, G. R; SANTOS, SANTOS, J. S.; CUNHA, F. S. A.; SILVA, R. A. C.; T. C.; PINTRO, P. T. M. By-product of passion-fruit SOARES, A. L. S. Farelo de palma da alimentação de seed (Passiflora edulis) in the diet of broilers. Canadian codornas. Revista Eletrônica Nutritime. 2017, 14, 5093- Journal of Animal Science. 2017, 98, 109-118. 5099. 